Citation: Hirt, C. (2013), RTM gravity forward-modeling using topography/bathymetry data to improve high-degree global geopotential models in the coastal zone, Marine Geodesy 36(2) :1-20, DOI: 10.1080/01490419.2013.779334.

\title{
RTM gravity forward-modeling using topography/bathymetry data to improve high-degree global geopotential models in the coastal zone
}

\section{Christian Hirt}

Western Australian Centre for Geodesy \& The Institute for Geoscience Research, Curtin University of Technology, GPO Box U1987, Perth, WA 6845, Australia

Email: c.hirt@curtin.edu.au

\section{Summary}

We apply the residual terrain modeling (RTM) technique for gravity forward-modeling to successfully improve high-resolution global gravity fields at short spatial scales in coastal zones. The RTM scheme is combined with the concept of rock-equivalent topography, allowing to use a single uniform constant mass-density in the RTM forward-modeling, both at land and sea. SRTM30_PLUS bathymetry is merged with higher-resolution SRTM V4.1 land topography, and expanded into spherical harmonics to degree 2160, yielding a new and consistent high-degree RTM reference surface. The forward-modeling performance is demonstrated in coastal zones of Greece and Canada using ground-truth vertical deflections, gravity from land and shipborne gravimetry, and geoid heights from GPS/leveling, with improvements originating from bathymetry clearly identified. We demonstrate that the SRTM30_PLUS bathymetry carries information on gravity field structures at spatial scales less than 5 arc minutes, which can be used to augment EGM2008 in (rugged) coastal zones, both over land and marine areas. This may be of value (i) to partially reduce the signal omission error in EGM2008/GOCE-based height transfer in areas devoid of dense gravity data, (ii) to fill the gap between land gravity and shipborne gravity along rugged coastlines and (iii) for the development of next-generation altimetric gravity fields.

Keywords: Residual terrain model, topography, bathymetry, coastal zone, forward-modeling

\section{Introduction}

Accurate determination of Earth's gravity field in coastal zones can be a challenging task. While land gravity can be observed - in principle with arbitrary density - close to the shorelines, shipborne gravity is restricted to marine areas which are safe to navigate (e.g., Featherstone 2010). Compared to land gravity observations, shipborne gravity can be of rather scarce 
coverage in coastal zones, e.g., of Australia (e.g., Claessens 2012) and USA (Andersen et al. 2010a; Featherstone 2010). Shipborne gravity data bases can also be contaminated by biases, which, however, can be reduced through cross-over adjustments (e.g., Denker and Roland 2005; Featherstone 2009).

Satellite altimetry currently resolves the gravity field over marine areas somewhat better than $\sim 5$ arc minutes (Andersen et al. 2010b) with improvements in resolution expected from the ongoing Cryosat mission (Sandwell et al. 2011; Andersen and Stenseng 2012). Though marine gravity determination from satellite altimetry has witnessed much improvement over the years, e.g., through re-tracking techniques (Deng et al. 2001; Hwang et al. 2006; Sandwell and Smith 2009; Andersen et al. 2010a,b), coastal zones remain problematic. Problematic areas include tide corrections or back-scatter from land points; e.g., Featherstone 2010; Deng et al. 2002), and increased error levels have been observed for altimetry fields in the vicinity of the coast (e.g., Claessens 2012; Andersen et al. 2010a; Hwang et al. 2006).

Airborne gravimetry (e.g., Forsberg and Olesen 2010) is capable of closing the gap between high-quality land gravity (if available) and marine altimetric gravity fields which are of good quality over the open oceans (Andersen et al. 2010a). Though some coastal zones are now covered with airborne gravimetry (e.g., Greenland, Germany) and initiatives exists (e.g., USA), airborne observations are not (yet) available over most of Earth's coastal zones, and alternative solutions are useful to improve gravity modeling in coastal zones.

Digital topographic elevation models (DTM; e.g., from the Shuttle Radar Topography Mission SRTM) and bathymetric depth models (DBM; from depth soundings or altimetry) carry information on the short-scale gravity field in coastal zones, and can be used to augment and improve global gravity fields, as is shown in the present paper. To extract the short-scale gravity information from DTM/DBM models, the elevations and depths are high-pass filtered (through subtraction of a long-wavelength reference surface), and then converted to gravity effects using forward-modeling techniques, specifically the residual terrain modeling (RTM) approach (Forsberg 1984).

DBMs were used successfully to forward-model high-frequency gravity signals, e.g., for smoothing of marine geoids from altimetry (Forsberg 1984, Sect. 10 ibid), for collocation-based prediction of marine gravity (Basic and Rapp 1992), in remove-compute-restore (RCR) geoid computations over marine areas of Canada (Vergos and Sideris 2003), Greece (Vergos and Sideris 2005), and Argentina (Tocho et al. 2005), for RCR-type interpolation and prediction of marine gravity data in Australian waters (Sproule et al. 2003; Sproule 2005). Combined DBM/DTM data were used in coastal zone geoid modeling, e.g., by Dahl and Forsberg (1998), for the reduction of vertical deflections in Greece (Somieski 2008), in RCR-type gravity predictions (Delikaraoglou et al. 2009), for topographic/bathymetric reductions of observed 
geoid heights (Limpach 2009) and for forward-modeling of short-scale gravity and geoid effects over Greece (Tziavos et al. 2010). To augment the high-resolution EGM2008 global gravity field (Pavlis et al. 2012) over marine areas beyond the EGM2008 resolution of 5 arc minutes, Tocho et al. (2012) tested RTM high-frequency effects offshore Argentina, however with limited success (discussed later).

The present study revisits the RTM forward-modeling technique along with DTM/DBM data with the goal to improve high-resolution global gravity fields (here EGM2008) at short spatial scales (less than 5 arc minutes) in coastal zones. Our work differs from the above studies for the following reasons.

First, we merge SRTM30plus (Becker et al. 2009) 30 arc-second bathymetry with higherresolution SRTM V4.1 topography (Jarvis et al., 2008) as RTM input data. While a similar merging strategy was used by Delikaraoglou et al. (2009) along with the degree-360 EGM96 model for smoothing of observed gravity in a RCR-type interpolation, we exploit here [much finer] short-scale information of the SRTM30plus/V4.1 merger to augment the degree-2190 EGM2008 model beyond 5 arc-min resolution.

Second, we combine Forsberg's (1984) RTM scheme with the concept of rock-equivalent topography (RET, e.g., Balmino et al. 1973) over marine areas. Compressing the ocean water masses to RET is convenient because it allows us to use a single uniform constant mass-density in the RTM forward-modeling, both at land and sea.

Third, instead of taking simple moving averages to generate the long-wavelength RTM reference surface, we use a new high-degree spherical harmonic RET, derived through spherical harmonic analysis. Our reference surface improves the construction of the RTM data for the purpose of GGM-augmentation in the coastal zone.

Finally, we test the performance of the RTM forward-modeling for three frequently used gravity field functionals (vertical deflections, gravity from land/ shipborne gravimetry, and geoid heights from GPS/leveling) in coastal zones of Greece and Canada, and place a focus on identification of improvements originating from inclusion of bathymetry. Our tests demonstrate that RTM forward-modeling, as described and carried out here, can be effective in delivering information on the short-scale gravity field in coastal zones which is not represented by high-degree geopotential models such as EGM2008. The approach described and tested may be of value to improve high-degree global gravity fields in some coastal applications (see discussion and conclusions) as long as no airborne gravimetry is available or accessible. Depending on the resolution and accuracy of airborne gravimetry, the approach could still be useful, even when airborne gravity data exist. 
One might argue that using bathymetric depths from altimetry to refine marine altimetric gravity (as contained in 5 arc-min EGM2008 over the oceans) is a cyclic procedure. However, with the approach taken here, spectral information down to 5 arc-min is removed from the bathymetric data through the high-pass filtering. As a consequence, both model components (EGM2008, and forward-modelled gravity from high-pass filtered bathymetry at scales less than 5 arc-min) should be largely complementary, specifically where soundings were used to constrain the DBM. However, some unwanted correlation may be present in both components as a result of increased error levels of altimetric products near the coast.

\section{Data and methods}

\subsection{DTM/DBM and merging}

The ingredients for the coastal zone RTM gravity forward-modeling are high-resolution DTM and DBM. Earth's topography is generally known to higher resolution than its bathymetry, and this is manifested by the resolution gap of available global DTM and DBM. One of the highestresolution combined DTM/DBM model is the 30 arc-second resolution SRTM30_PLUS V.7.0 model (Becker et al. 2009) that is combined here with the hole-filled SRTM V4.1 release (Jarvis et al. 2008) to exploit the higher resolution of SRTM data over land.

SRTM30_PLUS uses the elevations from the SRTM mission (Farr et al. 2007) over land areas, and $\sim 298$ million depth soundings edited and combined with seafloor topography estimates from altimetry (e.g., Smith and Sandwell 1997). According to Becker et al. (2009), about 10\% of their seafloor estimates can be considered constrained by soundings (at 1 min resolution), with more soundings processed near the coast and continental margins than over the ocean basins. We select the hole-filled 250m-resolution (7.5 arc second) SRTM V4.1 model because it performs reasonably well in RTM forward-modeling of gravity field functionals over land areas (e.g., Hirt 2010; Hirt 2012). The 7.5 arc second resolution of the V4.1 release exceeds those of the SRTM30_PLUS bathymetry by factor 4, so is [more than] good enough to study the contribution of the lower-resolution bathymetry. The formal SRTM30_PLUS resolution exceeds those of EGM2008 by a factor of $\sim 10$, which is why the bathymetric component of this data set was selected for our coastal short-scale gravity forward-modeling.

We merged the 7.5 arc second SRTM V4.1 model with the SRTM30_PLUS bathymetry in a two-step procedure, by first increasing its 30 arc second resolution to 7.5 arc second (using bicubic interpolation), before inserting the 30_PLUS bathymetric depths into the V4.1 release over ocean areas. Oceans were distinguished from land using the SRTM water body data set that is included in the SRTM4.1 release. Outside the SRTM4.1 coverage (that is, at high latitudes outside $60^{\circ}$ North and $56^{\circ}$ South) SRTM30_PLUS is used (see Becker et al. 2009 for details on 
the data sources). The result of the combination, the SRTM4.1/SRTM_30PLUS merger is abbreviated here to SRTM-C (combined).

\subsection{Rock-equivalent topography}

In our coastal RTM forward-modeling, the mass-density of standard topographic rock ( $\rho=2670$ $\mathrm{kg} \mathrm{m}^{-3}$ ) is used to represent land points, as well as the seafloor topographic masses (alternatively, smaller mass-density values could be used for the sediments, if known). The ocean water masses are properly represented through a mass density of $\rho_{\mathrm{W}}=1030 \mathrm{~kg} \mathrm{~m}^{-3}$. To avoid the need to distinguish between different density values in the forward-modeling step (and use of two different reference surfaces), we make use of the concept of rock-equivalent topography (RET, e.g., Balmino et al. 1973; Rummel et al. 1988; Hirt et al. 2012). In the RET approach, the ocean water masses are 'compressed' into equivalent rock masses by reducing the ocean depths $(H<0)$ by factor $\left(1-\rho_{\mathrm{W}} / \rho\right) \approx 0.614$ to equivalent rock heights $H^{*}$

$$
H^{*}=H\left(1-\rho_{\mathrm{W}} / \rho\right)
$$

Eq. 1 is applied for all $\mathrm{H}<0$ where the SRTM water body data set indicates ocean areas, converting the SRTM-C to SRTM-CR (combined and rock-equivalent over the oceans). The use of RET is convenient because a single constant uniform mass-density (of topographic rock) can be used both over land and the now-compressed ocean water masses in the RTM forwardmodeling, thus there is no further need to discriminate between land and ocean points. As a drawback, the geometry of the ocean masses is changed (e.g., Kuhn and Featherstone 2003). As will be indirectly shown by the performance of the coastal RTM technique, this effect is acceptable near coastlines, where the sea floor topography is mostly shallow.

\subsection{Spherical harmonic reference surface}

The RTM approach requires a smooth, long-wavelength reference surface to be subtracted from the detailed elevation model (Forsberg and Tscherning 1981). Following Forsberg (1984), the reference surface can be either obtained through averaging the detailed elevation model, or "especially [] through a high-order spherical harmonic expansion of the topography of Earth" (ibid, p.37). If the RTM is used as augmentation of global geopotential models (GGM) beyond their maximum resolution (i.e., maximum harmonic degree $n$ ), subtraction of a spherical harmonic reference surface of the same degree is most suitable to high-pass filter the detail elevations.

While some studies use moving-average-filtering to construct RTM data over marine or coastal

zones (e.g., Tziavos et al. 2010; Tocho et al. 2012), we prefer to use a spherical harmonic reference surface. This is because spherical harmonic reference surfaces were found to perform 
significantly better than moving averages when RTM data is to be deployed as augmentation of GGMs at short scales (Hirt 2010). The suitability of spherical harmonic reference surfaces in RTM forward-modeling for the purpose of GGM-augmentation was early indicated by Forsberg (1984, p37 and p38).

Our goal is to augment the degree-2160 EGM2008 GGM (Pavlis et al. 2012) through RTM at scales less than 5 arc minutes, thus a spherical harmonic reference surface of identical resolution is required. The EGM2008-accompanied DTM2006.0 topography model (see Pavlis et al. 2007; 2012) is not rigorously compatible to our SRTM-CR model, even if the DTM2006.0 bathymetry was made rock-equivalent with Eq. (1). The most notable difference to Pavlis et al.'s DTM2006.0 data base is that our SRTM-CR uses SRTM30_PLUS and thus relies on depth soundings [where available] over the oceans, but differences also exist over land areas (see Pavlis et al. 2007; 2012 for the data sources used for their DTM2006.0). To yield a consistent reference surface, we expanded our SRTM-CR into spherical harmonics with the procedures detailed in Appendix A. The resulting spherical harmonic expansion of SRTM-CR, a set of spherical harmonic coefficients complete to degree and order 2160, is denoted here RET2012. RET2012 elevations are synthesized using

$$
H^{R E T 2012}=\sum_{n=0}^{n_{m \pi x}^{R E T 2012}} \sum_{m=0}^{n}\left(\overline{H C}_{n m}^{R E T 2012} \cos m \lambda+\overline{H S}_{n m}^{R E T 2012} \sin m \lambda\right) \bar{P}_{n m}(\cos \theta)
$$

where $n_{\max }^{R E T 2012}=2160$ is the maximum expansion degree, $\overline{H C}_{n m}^{R E T 2012}$ and $\overline{H S}_{n m}^{R E T 2012}$ are the $4 \pi$ fully-normalized spherical harmonic coefficients of RET2012, $\bar{P}_{n m}(\cos \theta)$ are the $4 \pi$-fullynormalized associated Legendre functions of degree $n$ and order $m$, and $\lambda$ is the longitude and $\theta$ is the geocentric co-latitude of the computation point.

Because the procedure to derive the RET2012 coefficients is somewhat cumbersome (see

Appendix A), our set of ( $\overline{H C}_{n m}^{R E T 2012}, \overline{H S}_{n m}^{R E T 2012}$ ) coefficients is publicly available for other users via http://www.geodesy.curtin.edu.au/research/models. The RET2012 harmonic coefficients are rigorously compatible to SRTM-CR (and thus SRTM30_PLUS in RET-representation over oceans, and the SRTM V4.1 release over land), allowing accurate high-pass filtering of the SRTM-CR detailed elevation grids.

\subsection{RTM forward-modeling of gravity effects}

RTM elevations are formed as differences between the 7.5 arc second SRTM-CR and the RET2012 spherical harmonic elevations with $n_{\max }^{R E T 2012}=2160$. The RTM represents mass-prisms of standard topographic rock density, and possesses spectral energy at scales shorter than 5 arc 
minutes. The conversion of the RTM elevations to RTM gravity effects is done based on the well-known forward-modeling procedure described in Forsberg (1984), whereby numerical prism integration is performed within a circular cap of some radius around the computation point to obtain the gravitational potential of the RTM-topography, as well as RTM geoid heights, gravity disturbances and vertical deflections (see, e.g., Forsberg and Tscherning 1981; Forsberg 1984; Nagy et al. 2000 for the equations). In our RTM/RET forward-modeling, the evaluation points are located at the RTM-topography, which coincides with the SRTM topography over land, while this surface is located under the ocean surface due to the RET-compression.

The RTM integration radius depends on the gravity functional (geoid or derivatives of the disturbing potential such as gravity and vertical deflections), as well as on the spectral energy of the RTM elevations. For RTM geoid heights (and the spatial scales shorter than 5 arc-min modelled here), an integration radius of $\sim 200 \mathrm{~km}$ is suitable (Hirt et al. 2010a). For derivatives of the potential (gravity and vertical deflections) a cap of some $\sim 10$ s of $\mathrm{km}$ is sufficient (see Hirt 2010). The RTM forward-modeling procedure was applied with success over land areas to spectrally augment EGM2008 beyond its 5 arc minute resolution (e.g., Hirt 2010, Hirt et al.

2010a,b, Šprlák et al. 2012), and a band-limited variant was used in the construction of EGM2008 over some areas of Earth (see Pavlis et al. 2007; Pavlis et al. 2012). As a principal drawback of the RTM-augmentation technique, information on short-scale anomalous gravity structures (i.e., signals not generated by the modeled topography/bathymetry) is not recovered, see also Pavlis et al. (2007).

The gravity forward-modeling procedure relies on the assumption of uncompensated topography. According to Torge (2001, p.340), topographic "loads of several 10 to $100 \mathrm{~km}$ dimensions are supported by the strength of the lithosphere and are not isostatically compensated"'. Our forward-modelled gravity effects possess spectral energy at spatial scales of less than $10 \mathrm{~km}$, which is why the assumption should be well justified.

\section{Comparisons and analyses}

Numerical tests were performed over coastal test areas in Greece and Canada with observed vertical deflections, gravity accelerations and geoid undulations available serving as groundtruth. In all of our tests, we compare the observed values with the corresponding functional from EGM2008, and with EGM2008 plus the RTM-modeled short-scale contribution from SRTMCR/RET2012 data. EGM2008 is evaluated in spectral band of degrees 2 to 2190 (the latter being compatible with the degree 2160 used in the RET2012 expansion, cf. Hirt et al., 2010b). The EGM2008 functionals were synthesized at the 3D-coordinates (geodetic latitude, longitude and ellipsoidal height) of the observations using the gradient approach for efficient 3D harmonic synthesis (see Hirt 2012 for details) and a modified version of the harmonic_synth software 
(Holmes and Pavlis 2008). RTM-functionals were forward-modeled using a variant of Forsberg's TC program (Forsberg 1984), $200 \mathrm{~km}$ integration radius for geoid undulations and $35 \mathrm{~km}$ radius for vertical deflections and gravity effects. All RTM quantities were computed in terms of $0.002^{\circ}$ resolution grids covering our test areas and bicubically interpolated at the locations of the comparison data.

\subsection{Greece test area}

Over the Greece test area, we use a set of 27 astrogeodetic vertical deflections (Müller et al. 2007; Somieski 2008). The data set can be considered unique because it is the only vertical deflection data set observed with a precise digital zenith camera system (Bürki et al. 2004) in the coastal zone, and regionally distributed over numerous islands in the North Aegean Sea (Fig. 1). The deflections were estimated to be accurate to $\sim 0.15$ arc seconds (Müller et al. 2007), so have ground-truth character. The input data for the RTM forward-modeling are exemplified in Fig. 1A (SRTM-CR detailed elevations), Fig 1B (RET 2012 spherical harmonic elevations), and Fig 1D (RTM = SRTM-CR minus RET2012). The descriptive statistics of the comparisons between the observed vertical deflections and EGM2008, as well as EGM2008 augmented by RTM are reported in Table 1 , and the residuals among the observations and modelled deflections are shown in Fig 1C (EGM2008-only) and Fig. 1D (EGM2008 + land/sea RTM). Inclusion of RTM land/sea data improves the RMS-agreement by close to $~ 50 \%$, from 1.86 to 0.99 arc seconds for the North-South component $\xi$, and 2.53 to 1.29 arc seconds for $\eta$ (Table 1 ).

Table 1

Descriptive statistics of vertical deflection comparisons over Greece, 27 stations with observed North-South (xi) and East-West (eta) vertical deflection, units in arc seconds, Impr = RMS improvement in percent.

\begin{tabular}{llllllll}
\hline Functional & Variant & RTM & Min & Max & Mean & RMS & Impr \\
\hline xi & Obs-EGM08 & No & -3.95 & 2.74 & -0.66 & 1.86 & \\
& Obs-(EGM08+RTM) & Land-only & -3.30 & 2.46 & -0.61 & 1.35 & 27.3 \\
& Obs-(EGM08+RTM) & Sea-only & -3.00 & 2.21 & -0.50 & 1.54 & 17.5 \\
& Obs-(EGM08+RTM) & Land/sea & -2.17 & 1.94 & -0.44 & 0.99 & 46.7 \\
& Obs-EGM08 & No & 4.47 & 4.94 & 0.67 & 2.53 & \\
& Obs-(EGM08+RTM) & Land-only & -1.88 & 2.69 & 0.42 & 1.43 & 43.5 \\
& Obs-(EGM08+RTM) & Sea-only & -3.91 & 4.33 & 0.63 & 2.35 & 7.3 \\
& Obs-(EGM08+RTM) & Land/sea & -1.59 & 2.97 & 0.38 & 1.29 & 49.0 \\
\hline
\end{tabular}


A

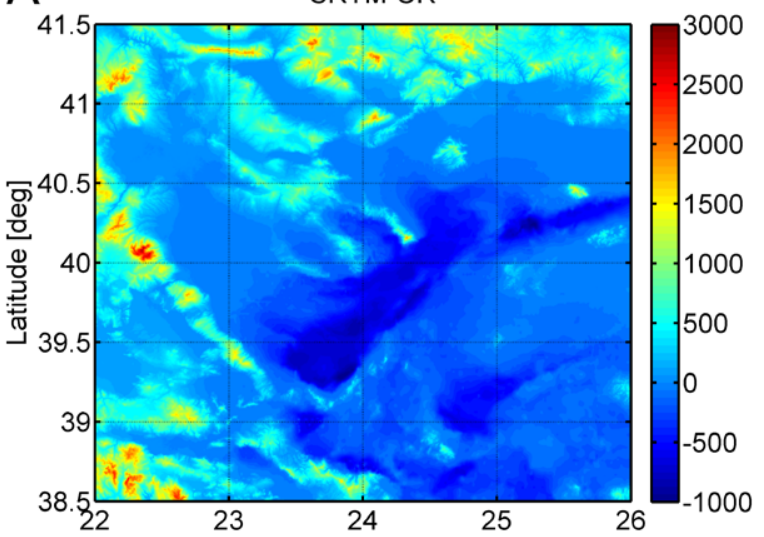

C

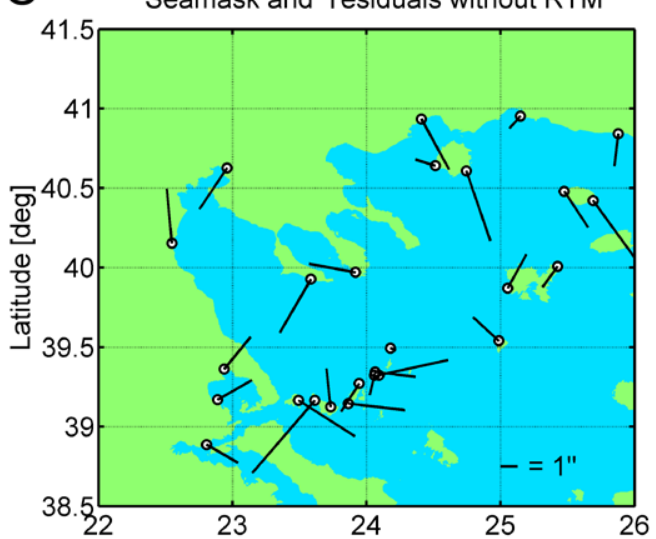

$\mathrm{E}$

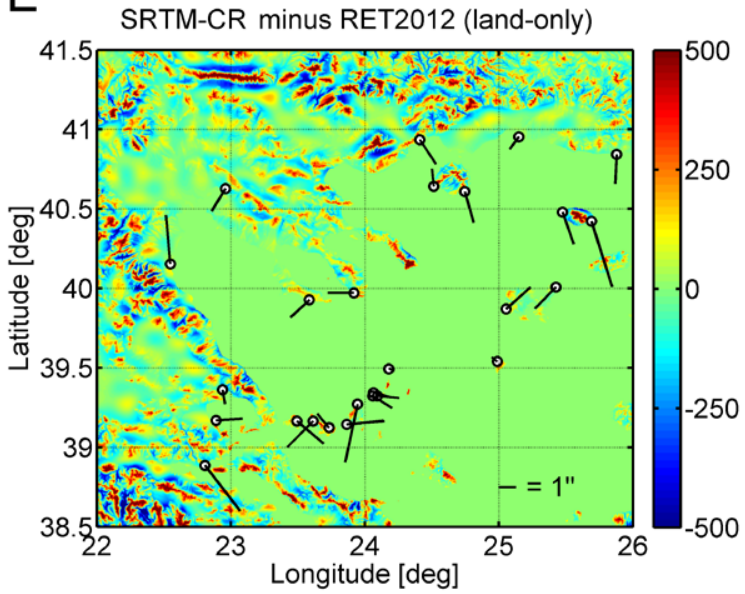

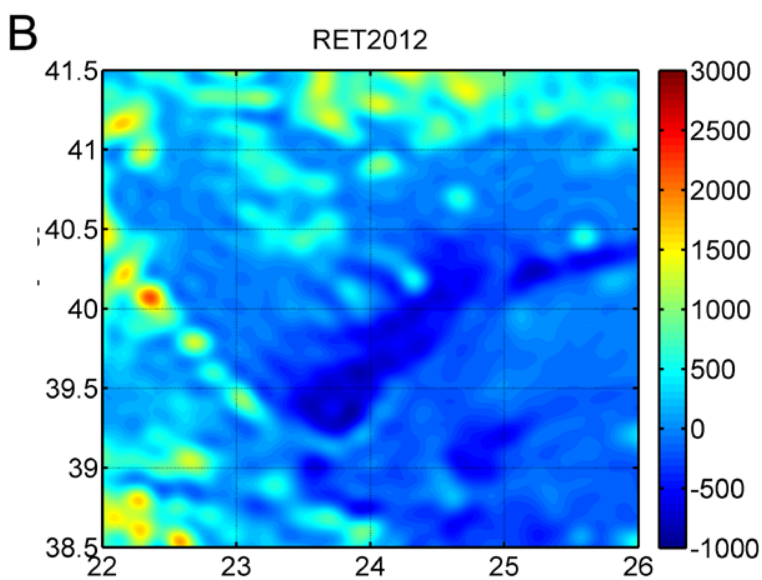

$\mathrm{D}$

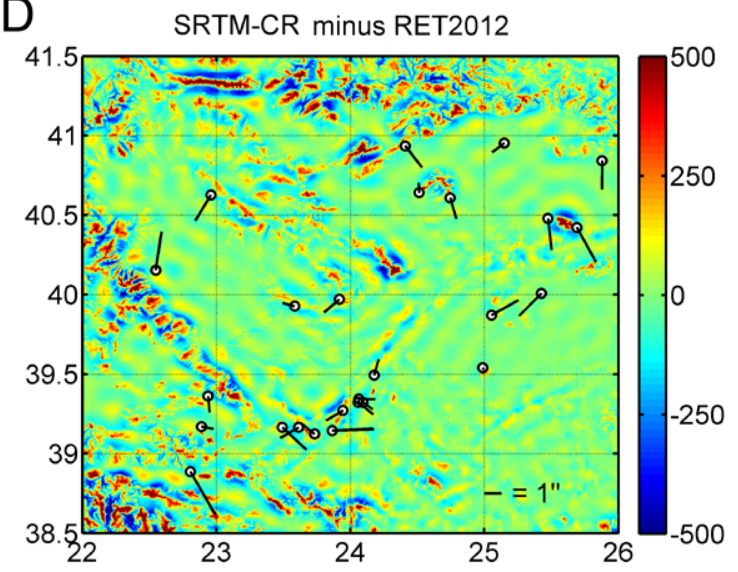

$\mathrm{F}$

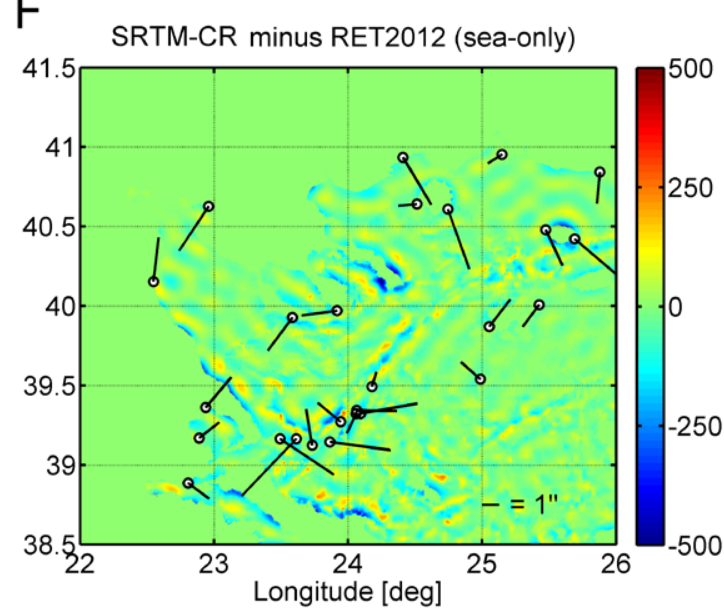

Figure 1. RTM forward-modeling and residuals between observed and modelled vertical deflections over Greece. A: SRTM-CR elevations, B: RET2012 spherical harmonic elevations to degree 2160 (derived from SRTM-CR), C: sea mask used to combine topography and bathymetry, D: land/sea RTM, E: land-only RTM, F: sea-only RTM, units in meters. Panels C-F also show the residuals between the observations and four model variants. 
In order to isolate the contributions coming from land and sea RTM data, RTM vertical deflections were forward-modeled using land-only data by setting the RTM over sea points to zero (Fig 1E). Conversely, the RTM bathymetric contribution was isolated by setting the land points to zero (Fig 1F). From Table 1, both variants independently improve the agreement among observations and EGM2008, with the land-only contributions being higher ( $27 \%$ and $~ 44 \%$ for $\xi$ and $\eta$, respectively) than those of the sea-only RTM data ( $\sim 18 \%$ and $\sim 7 \%)$. In a relative sense, this is not surprising, bearing in mind that the topography is (much) better resolved over land through the SRTM data, than the DBM. Unmodeled mass-density variations of sediment layers might play some role as well.

From Table 1, bathymetry data makes a contribution to the RTM forward-modelled vertical deflection, and improves over land-only RTM modeling. This is further corroborated by an analysis of the reductions of total residuals $\delta \Delta \varepsilon$ due to including bathymetry. To obtain $\delta \Delta \varepsilon$, we first computed the total residuals $\Delta \varepsilon_{l}$ using the land-only RTM

$$
\begin{aligned}
& \Delta \xi_{l}=\xi^{\text {astro }}-\left(\xi^{E G M 2008}+\xi_{\text {land-only }}^{R T M}\right) \\
& \Delta \eta_{l}=\eta^{\text {astro }}-\left(\eta^{E G M 2008}+\eta_{\text {land-only }}^{R T M}\right) \\
& \Delta \varepsilon_{l}=\sqrt{\Delta \xi_{l}^{2}+\Delta \eta_{l}^{2}}
\end{aligned}
$$

and $\Delta \varepsilon_{l / s}$ using land/sea RTM data

$$
\begin{aligned}
& \Delta \xi_{l / s}=\xi^{\text {astro }}-\left(\xi^{E G M 2008}+\xi_{\text {land } / \text { sea }}^{R T M}\right) \\
& \Delta \eta_{l / s}=\eta^{\text {astro }}-\left(\eta^{E G M 2008}+\eta_{\text {land } / \text { sea }}^{R T M}\right) \\
& \Delta \varepsilon_{l / s}=\sqrt{\Delta \xi_{l / s}{ }^{2}+\Delta \eta_{l / s}{ }^{2}}
\end{aligned}
$$

respectively, to yield the reduction in total residuals

$$
\delta \Delta \varepsilon=\left|\Delta \varepsilon_{l}\right|-\left|\Delta \varepsilon_{l / s}\right|
$$

which are shown in Fig. 2. Inclusion of bathymetry reduces the total residuals for 19 out of 27 stations, with clear improvements (0.5 arc seconds or more) for 11 stations, and clear deterioration (of about 0.5 arc seconds) visible for only one station. It is the sea-only RTM elevation data from SRTM30_PLUS shown in Fig. 1F that provides some missing information on the short-scale marine gravity field not recoverable by land-only RTM, nor resolved by the 5arcmin EGM2008 model. The Greece vertical deflection data set was also used in Hirt et al. (2010b) for assessment of EGM2008, however, without attempting to model the RTM contributions over sea. As such, the land-only RTM case (Fig. 1E) corresponds closely to the comparisons done by Hirt et al. (2010b). It is acknowledged that one outlier was not removed in 
Hirt et al. (2010b) (they used 28 instead of the 27 vertical deflection stations also used by Müller et al. 2007).

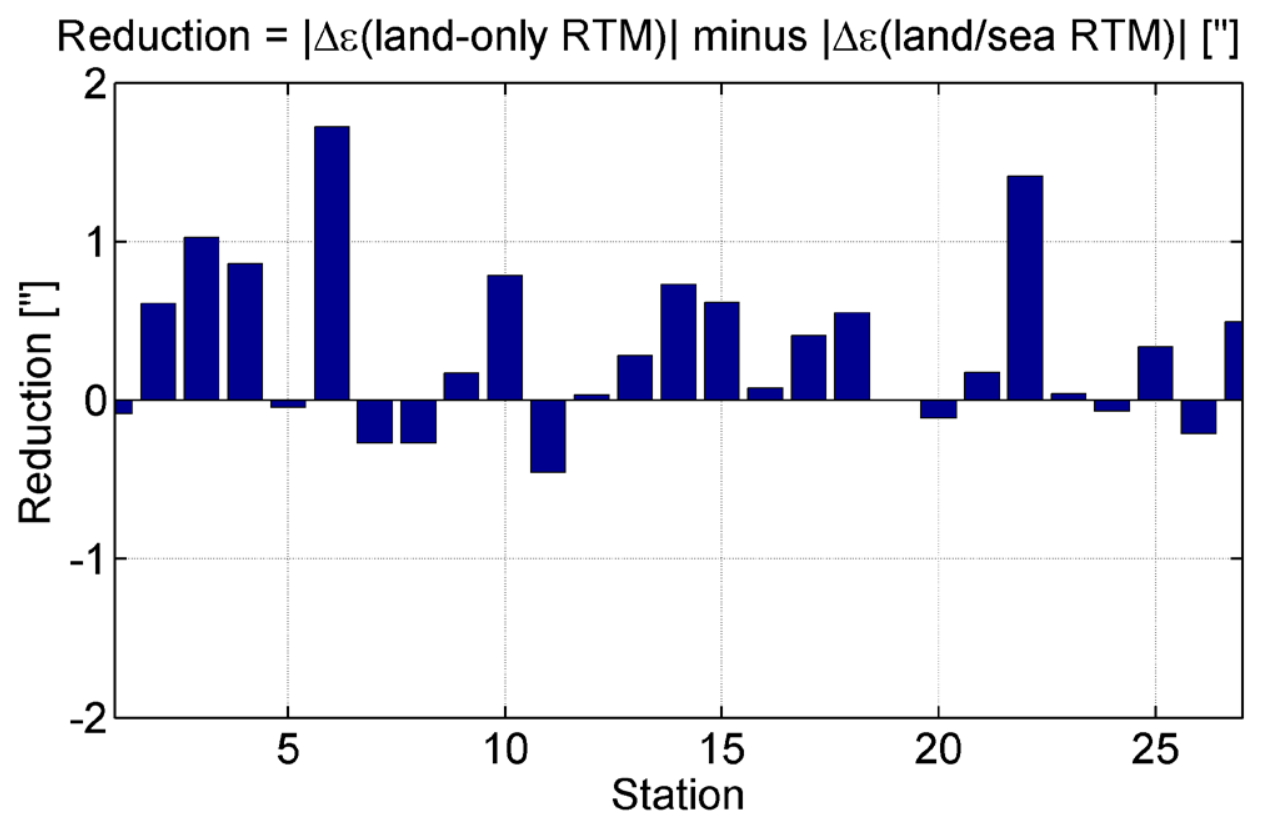

Figure 2. Reduction of vertical deflection residuals through inclusion of bathymetry in the RTM forward-modeling, shown as a function of the station, units in arc seconds.

\subsection{Vancouver test area}

As second test area, the Vancouver coastal zone (bounded by $-130^{\circ} \leq$ longitude $\lambda \leq-122^{\circ}$ and $48^{\circ} \leq$ latitude $\varphi \leq 51^{\circ}$ ) including Vancouver Island and the Western Canadian mainland was selected because of its rugged bathymetry and topography, and because the Canadian gravity data base (NRC 2011) provides ample gravity observations both over land and at sea. Using the SRTM-embedded sea mask, 2711 land gravity stations were selected within a $10 \mathrm{~km}$ land zone near the coast, as well as 15544 sea gravity measurements within a $10 \mathrm{~km}$ sea zone adjoining the coast line (Fig. 3). While the SRTM sea mask rigorously separates between SRTM V4.1 and SRTM30_PLUS data, a strict separation between terrestrial and ship-track data in the immediate vicinity of the coast line will not always be possible due to the discretisation of 7.5 arc seconds. Given the $10 \mathrm{~km}$ width of our land and sea zones, the impact of the sea mask resolution is believed to be rather small on our results. Additionally, a set of geoid heights at 56 GPS/leveling stations is used that is based on the Nov07 adjustment of the Canadian leveling network (Véronneau 2007; Véronneau et al. 2006), cf. Fig. 3. 


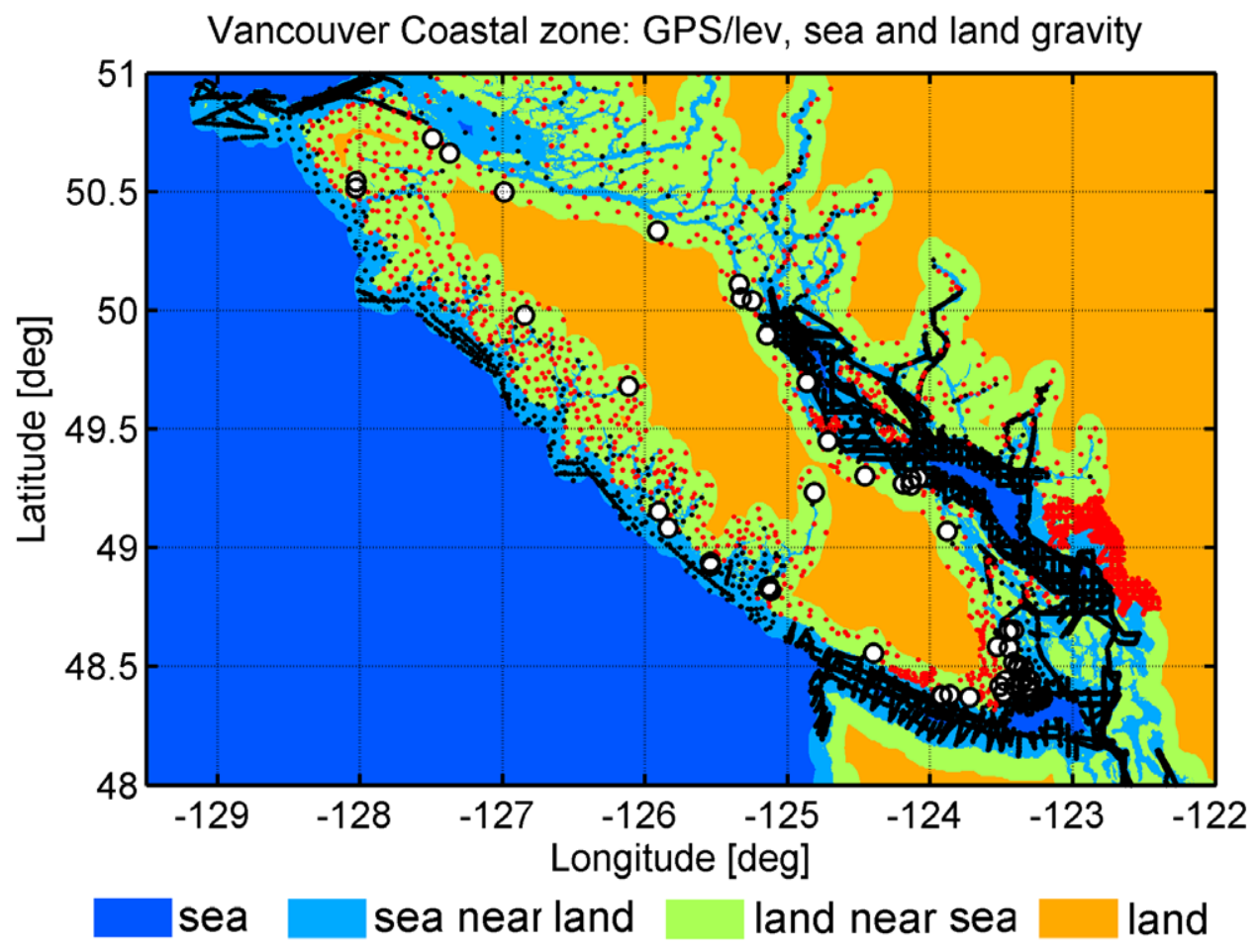

Figure 3. Land gravity (red), sea gravity (black) and GPS/levelling points (circles) over the Vancouver test area.

The comparisons between observed and modelled gravity (Table 2) were drawn separately for the land and sea gravity stations and for the model variants

(i) EGM2008-only,

(ii) EGM2008+RTM (land-only, through setting RTM elevations over sea to zero),

(iii) EGM2008+RTM (sea-only, through setting RTM elevations over land to zero), and

(iv) EGM2008+RTM (land/sea, i.e., using the full RTM information from our topography-bathymetry combination),

allowing investigation of the role of bathymetry in our RTM-modeling. In all of our tests, we transformed the observed gravity values to gravity disturbances by subtracting the GRS80 normal gravity at ellipsoidal station height. Because the Canadian gravity stations are accompanied by physical heights, ellipsoidal station heights had to be constructed by applying the EGM2008 geoid as correction. 


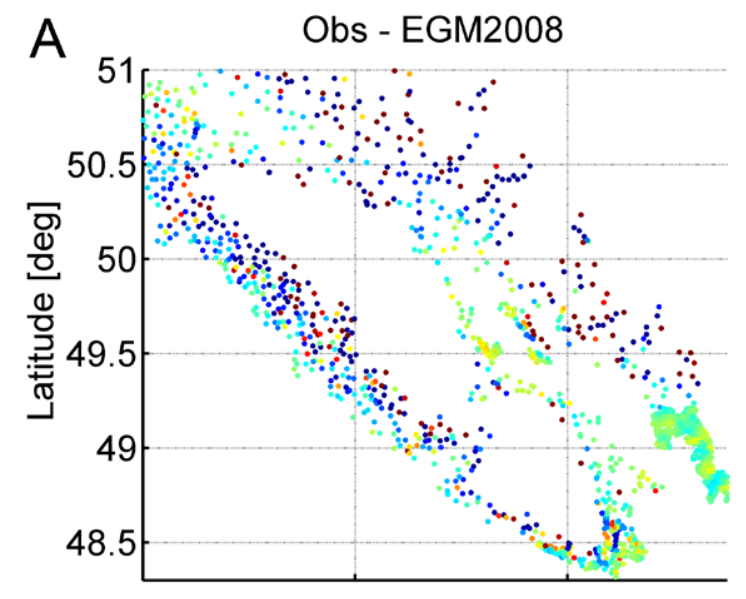

B Obs - (EGM2008 + RTM land-only)
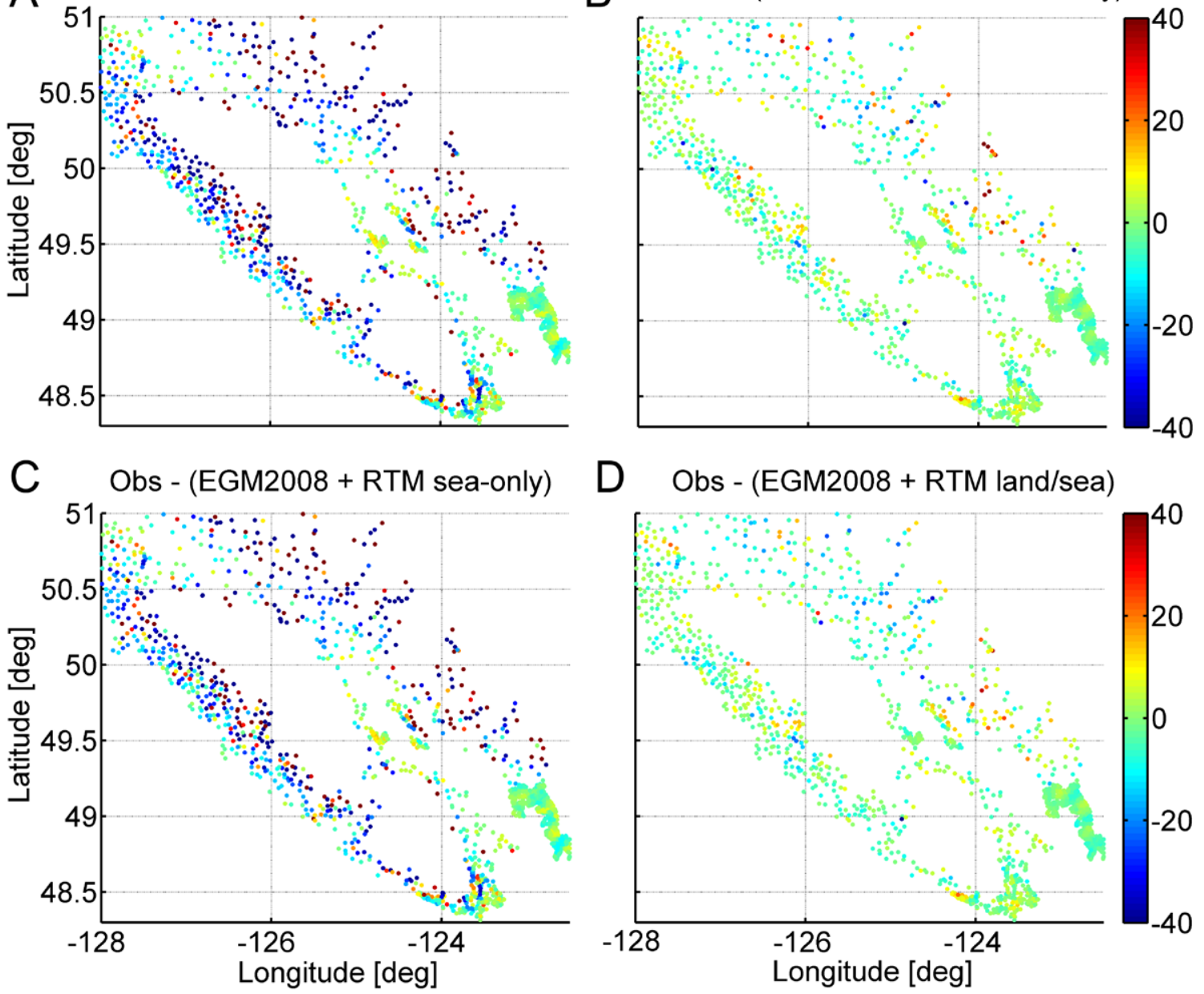

Figure 4. Residuals between observed and modelled gravity disturbances at 2711 land stations near the coastline of the Vancouver test area. A: Comparison between observations and EGM2008, B: Observations compared with EGM2008 and RTM (land-only), C: Observations compared with EGM2008 and RTM (sea-only), D: Observations compared with EGM2008 and RTM (land and sea), unit in mGal.

For the land gravity stations, Fig. 4 shows the residuals 'observation minus model' for the four different cases. From Table 2, RTM considerably improves the RMS-agreement by 70\% over the EGM2008-only solution. The improvement is largest when including land and sea points in the RTM forward-modeling ( 73 \%, from 21.1 to $5.8 \mathrm{mGal}$ ), compare Fig. 4A and 4D. Using sea-only RTM, our land gravity comparisons indicate 6\% RMS improvement, while the landonly RTM yields a significant $\sim 70 \%$ gain in improvement (Figs. $4 \mathrm{~B}$ and $4 \mathrm{C}$ ). We note that similarly significant RTM-conferred improvements have been reported for other land areas, e.g., Norway (Šprlák et al. 2012), Switzerland (Hirt 2012) and Australia (Filmer et al. 2013). 

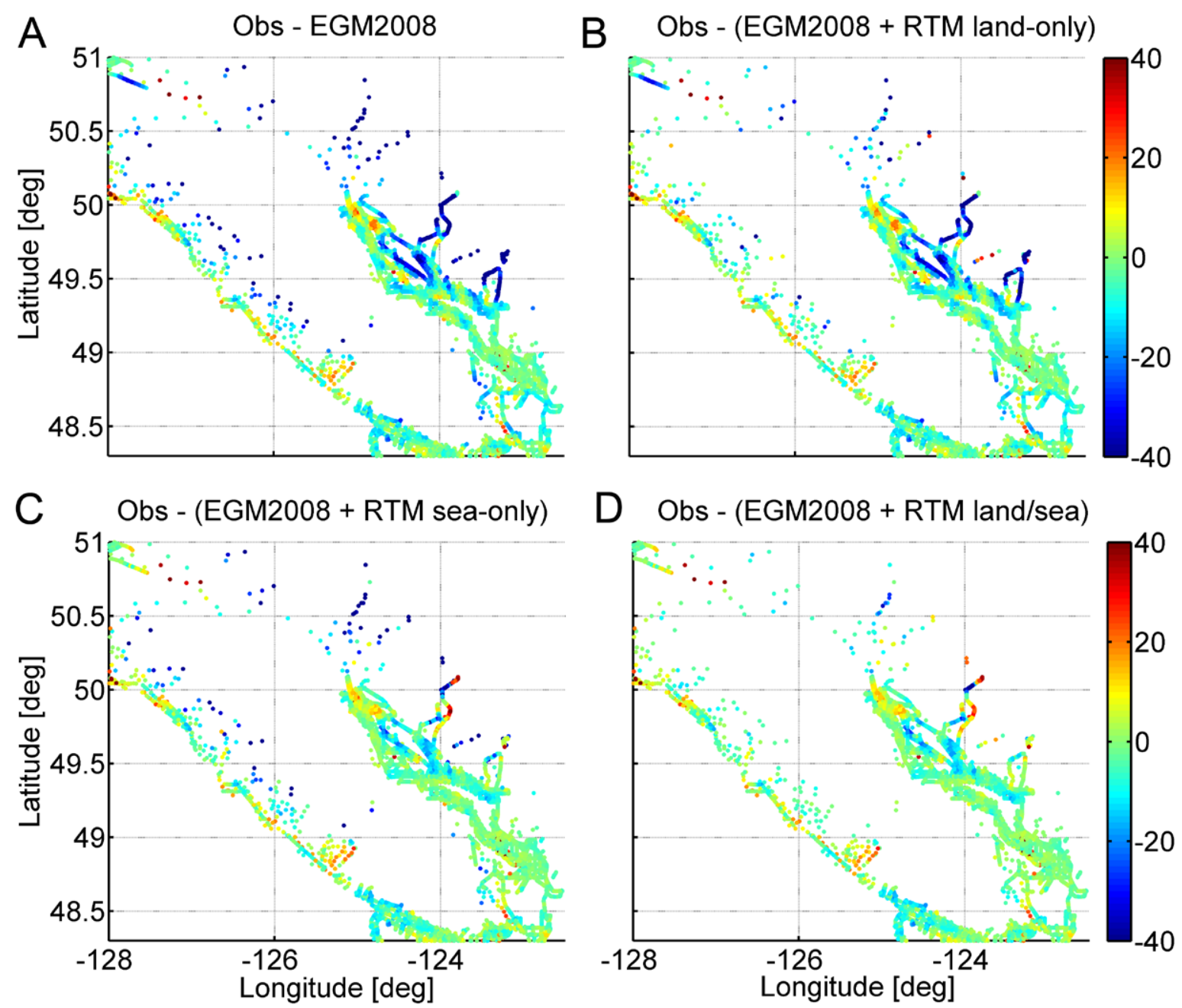

Figure 5. Residuals between observed and modelled gravity disturbances at 15544 sea stations near the coastline of the Vancouver test area, unit in mGal. See also caption of Figure 4.

For the sea gravity (see Fig. 5 for the residuals) using land-only RTM and EGM2008 reduces the RMS differences by $\sim 8 \%$ compared to EGM2008-only, while the sea-only RTM data and EGM2008 significantly improves the agreement ( 42 \%, from $14.6 \mathrm{mGal}$ down to $8.5 \mathrm{mGal}$ ). Consideration of both land and sea points in the RTM yields the highest improvement, as large as $\sim 50 \%$, (reduction of RMS-differences from 14.6 to $7.4 \mathrm{mGal}$, Figs. 5A and 5D). This behavior is within the expectations, given that the "RTM-terrain" closest to the station makes usually the largest contribution (cf. Forsberg 1984, Eq. 7.5 ibid), and the SRTM30_PLUS bathymetry thus has a larger impact on sea than land points in coastal zones (Figs. 5B and 5C). Both the land and sea gravity sets unanimously demonstrate that the SRTM30_PLUS-conferred bathymetric information improves the agreement between EGM2008 and observations and between EGM2008 and land-only RTM data, not only over land but also sea near the coast. 
Table 2 Descriptive statistics of gravity disturbance comparisons over the Vancouver Island area (Western Canada), 2711 land gravity stations and 15544 sea gravity stations used, unit in $\mathrm{mGal}$, Impr = RMS improvement in percent.

\begin{tabular}{llllllll}
\hline Functional & Variant & RTM & Min & Max & Mean & RMS & Impr \\
& & & & & & & \\
\hline Land gravity & Obs-EGM08 & Not applied & 137.3 & 101.1 & -4.7 & 21.1 & \\
& Obs-(EGM08+RTM) & Land-only & -63.1 & 38.9 & -1.8 & 6.3 & 70.3 \\
& Obs-(EGM08+RTM) & Sea-only & -112.4 & 101.3 & -4.0 & 19.9 & 6.0 \\
& Obs-(EGM08+RTM) & Land/sea & -56.6 & 35.2 & -1.9 & 5.8 & 72.6 \\
& & & & & & & \\
& & & & & & & \\
& Obs-EGM08 & Not applied & -117.8 & 60.2 & -6.1 & 14.6 & \\
& Obs-(EGM08+RTM) & Land-only & -111.2 & 60.2 & -5.7 & 13.5 & 7.9 \\
& Obs-(EGM08+RTM) & Sea-only & -102.4 & 57.9 & -2.0 & 8.5 & 42.0 \\
& Obs-(EGM08+RTM) & Land/sea & -51.3 & 58.0 & -1.6 & 7.4 & 49.5 \\
& & & & & & & \\
\hline
\end{tabular}

Geoid heights were computed from EGM2008 following Hirt (2012) whereby Rapp’s (1997) C2 geoid-quasigeoid separation term was approximated with zero (because most stations are close to or at the sea level), and then augmented with RTM (land-only), RTM (sea-only) and RTM (land/sea) geoid heights. A bias was subtracted in the comparisons with the observed geoid undulations from the GPS/leveling data (Table 3). From Table 3, the land/sea RTM improves the RMS agreement over the EGM2008-only geoid heights by $12 \%$, or from 54 to $47 \mathrm{~mm}$ in terms of RMS differences. Using RTM (land-only) surprisingly deteriorates the RMS agreement to 77 mm (or $-42 \%$ ), while the RTM (sea-only) data alone yields RMS values equivalent to EGM2008-only. 
Table 3 Descriptive statistics of geoid comparisons over the Vancouver area at 56 GPS/levelling stations. Bias fit applied in all cases, unit in meters, Impr = RMS improvement in percent.

\begin{tabular}{llllll}
\hline Variant & RTM & Min & Max & RMS & Impr \\
\hline Obs-EGM08 & Not applied & -0.123 & 0.116 & 0.0539 & \\
Obs-(EGM08+RTM) & Land-only & -0.217 & 0.146 & 0.0767 & -42.4 \\
Obs-(EGM08+RTM) & Sea-only & -0.149 & 0.121 & 0.0535 & 0.6 \\
Obs-(EGM08+RTM) & Land/sea & -0.101 & 0.109 & 0.0474 & 12.0 \\
\hline
\end{tabular}

A closer inspection of the land-only RTM performance revealed that strongly negative RTM elevations of deep fjords and inlets (cf. Fig 3) in our test area were "neglected” [through setting the RTM elevations over sea to zero], introducing unwanted systematic error patterns (RTM geoid undulations with a positive bias of several cm near the rugged parts of the coast). Hence, a combination of topography/bathymetry data in RTM geoid modeling is to be preferred over landonly RTM in [rugged] coastal zones. This not only reduces systematic errors [of the land-only RTM] but improves over EGM2008-only geoid information in our test area. The lower geoid RMS-improvement rates in comparison to gravity and deflections are not surprising, bearing in mind that the geoid spectral power is concentrated in the long and medium wavelengths.

\subsection{Newfoundland test area}

Because it was felt that an area less rugged than the Vancouver area is useful to give a more complete picture of the RTM coastal zone modeling performance, we have chosen Newfoundland (Eastern Canadian Coast) as a third test area. The Newfoundland area is less elevated than the Vancouver area and features rather shallow bathymetry. 2321 land gravity and 1577 sea gravity stations were extracted from the Canadian gravity data base in $10-\mathrm{km}$ land and sea zones adjoining the coast line within $-60^{\circ} \leq \lambda \leq-52^{\circ}$ and $46^{\circ} \leq \varphi \leq 51^{\circ}$ (Figure 6). The comparisons were drawn in complete analogy to the Vancouver tests. 180 erroneous ship-track observations (based on an arbitrary threshold of 30mGal for the differences observations minus EGM2008/RTM gravity values) were identified near 53.5W and $47.6 \mathrm{~N}$, and South of $47.5 \mathrm{~N}$ and excluded from the analysis, ensuring that the sea gravity observations keep 'ground-truth' character. 


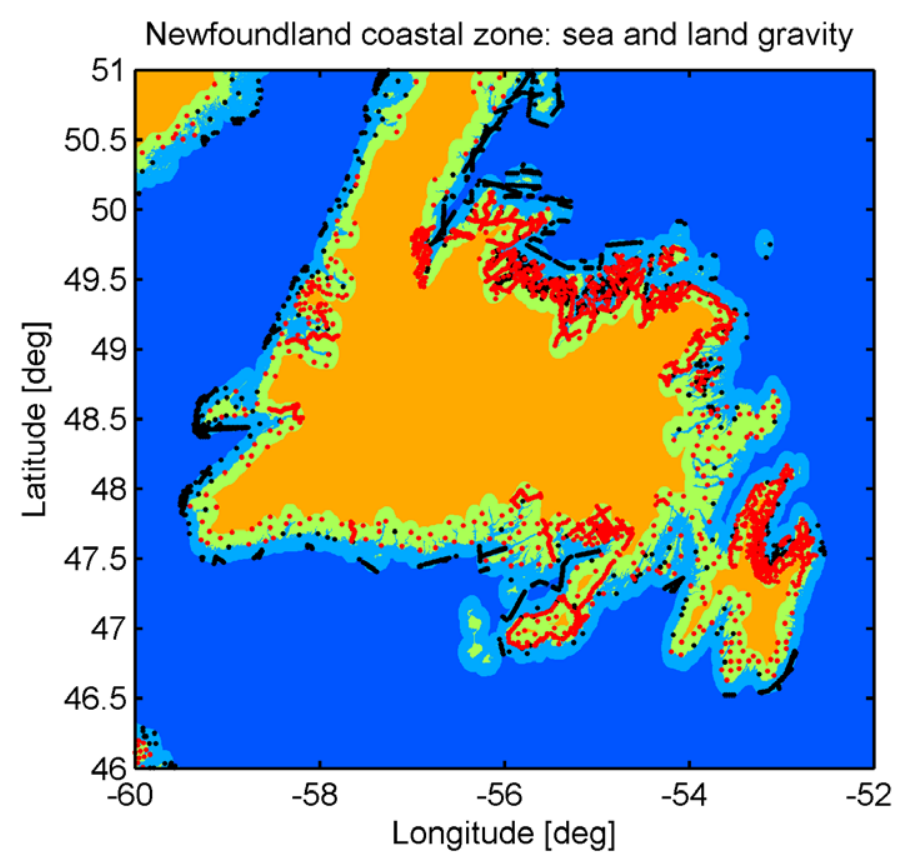

Figure 6. Land gravity (red) and sea gravity (black) over the Newfoundland test area. For legend see Figure 3.

Table 4 Descriptive statistics of gravity disturbance comparisons over New Foundland (Eastern Canada), 2321 land gravity stations and 1577 sea gravity stations used within $-60^{\circ} \leq \lambda \leq-52^{\circ}$ and $46^{\circ} \leq \varphi \leq 51^{\circ}$, units in mGal, Impr $=$ RMS improvement in percent.

\begin{tabular}{|c|c|c|c|c|c|c|c|}
\hline Functional & Variant & RTM & Min & Max & Mean & RMS & Impr \\
\hline \multirow[t]{4}{*}{ Land gravity } & Obs-EGM08 & Not applied & 55.3 & 42.7 & -1.2 & 7.8 & \\
\hline & Obs-(EGM08+RTM) & Land-only & -30.0 & 14.9 & -0.2 & 3.8 & 50.5 \\
\hline & Obs-(EGM08+RTM) & Sea-only & -53.6 & 42.7 & -1.1 & 7.5 & 3.2 \\
\hline & Obs-(EGM08+RTM) & Land/sea & -23.8 & 15.7 & 0.0 & 3.7 & 52.3 \\
\hline \multirow[t]{4}{*}{ Sea gravity } & Obs-EGM08 & Not applied & -28.1 & 30.4 & -3.7 & 6.8 & \\
\hline & Obs-(EGM08+RTM) & Land-only & -26.8 & 30.4 & -3.3 & 6.3 & 7.4 \\
\hline & Obs-(EGM08+RTM) & Sea-only & -25.5 & 27.5 & -2.7 & 6.1 & 10.9 \\
\hline & Obs-(EGM08+RTM) & Land/sea & -19.9 & 27.7 & -2.1 & 5.4 & 20.5 \\
\hline
\end{tabular}


From the descriptive statistics reported in Table 4, use of land/sea RTM as augmentation of EGM2008 yields the best agreement in all cases, with RMS improvement rates of 50\% (land gravity observations), and $\sim 20 \%$ (sea gravity). We observe that the SRTM30_PLUS bathymetry contributes to a slight improvement for the land gravity (RMS reduction from 7.8 to $7.5 \mathrm{mGal}$ ) and makes a somewhat clearer contribution in our sea gravity modeling (RMS reduction from 6.8 to $6.1 \mathrm{mGal}$, or $11 \%$ improvement over the EGM2008-only solution) near the coast. Again, the best agreement is obtained through combined use of topography and bathymetry, as indicated independently by the land and sea gravity. The test demonstrates that also in a less rugged coastal area our RTM topography/bathymetry-combined forward-modeling may confer advantages over “land-only” RTM-data.

\section{Discussion}

Over three coastal test areas with different characteristics, we have compared the performance of land-only RTM gravity forward-modeling with the more advanced RTM approach that combines SRTM land topography with SRTM30_PLUS bathymetry. The gravitational attraction of the ocean water masses was modelled as rock-equivalent topography, but this is only a computational preference. Three different gravity field functionals (geoid, gravity, vertical deflections) and three coastal test areas were used in order to make the performance tests more complete.

All of our tests unanimously demonstrate that the 30 arc-second SRTM30_PLUS bathymetry contains information on the gravity field's fine structure over our test areas, at spatial scales shorter than 5 arc-minutes. As such, the SRTM30_PLUS bathymetry is shown to be capable of improving EGM2008 both over land and marine areas in coastal zones. The contributions of the land topography (DTM) to the RTM-modelled short-scale gravity field were larger than of the DBM (also compare variations in land and sea RTM data in Figs. 1E and 1F). Considering the lower resolution of the SRTM30_PLUS bathymetry relative to the high-resolution SRTM land topography, this is within the expectations. In comparison to the DTM, the DBM component can thus be considered the 'bottleneck' in coastal zone RTM gravity forward-modeling.

A recent paper (Tocho et al. 2012) investigated topographic reductions in the context of RCR marine geoid computations using EGM2008. Tocho et al. (2012) deployed an altimetry-derived DBM [without depth soundings], used moving averages for constructing their RTM data, and investigated over a marine area offshore Argentina whether RTM improves the agreement between EGM2008 and higher-resolution altimetry-derived functionals. Tocho et al. (2012) found insignificant RTM-conferred improvements for gravity anomalies and no improvements

for geoid undulations. They concluded that the "spatial resolution of the currently available DBMs is not enough in order to provide high frequency content information compared to 
EGM2008 for marine gravity field and geoid modeling", while acknowledging the possible use of altimetry/sounding combined DBMs (Tocho et al., 2012, Sect.3 ibid).

Contrary to the Tocho et al.'s study, our Tables 1, 2, 3 and 4 demonstrate that the resolution of the SRTM30_PLUS DBM is good enough to provide higher-frequency content information compared to EGM2008 over some coastal areas. Key differences between Tocho et al.'s (2012) and our study are (i) the test areas (up to $\sim 700 \mathrm{~km}$ offshore vs. coastal as well as Southern vs. Northern Hemisphere), (ii) the DBMs employed (altimetry-only vs. altimetry/sounding combined) and (iii) the RTM forward-modeling approach (moving averages vs. spherical harmonic high-pass filtering and use of RET). The different findings of both studies are most likely explained by the fact that our tests focus on the coastal zone, where a reasonable amount of sounding data can be assumed to be available to constrain bathymetry from altimetry (see Wessel and Chandler 2011, Becker et al. 2009). Second, over the Northern Hemisphere coastal zones more soundings are available than over the Southern Hemisphere (Wessel and Chandler 2011). Third, also the filtering used in the construction of RTM data is different (mean values vs. the more suitable spherical harmonic filtering), which might also play a role.

We acknowledge that the SRTM30_PLUS bathymetry is not a perfect description of the seafloor topography in its entirety, with artifacts reflecting ship track data visible over parts of the oceans, and artifacts at some land-sea transitions apparently present. Naturally, forward-modeling of such "bad data" will yield poor or even wrong estimates of the gravity field's fine structure. In coastal zones with very shallow bathymetry/topography, such as most of the North Sea, it is clear that RTM elevations will be small, and thus RTM-conferred improvements insignificant. In the present study we did not test the RTM approach over remote offshore areas [nor Southern Hemisphere areas] where the spatial resolution of depth soundings may be lower and their distribution scarcer (see Becker et al. 2009; Wessel and Chandler 2011). Over deep ocean basins, the role of gravity attenuation with height remains to be investigated as a future task, while our coastal zone test results suggests that over shallow waters attenuation effects are sufficiently accounted for.

\section{Conclusions}

This study has investigated RTM forward-modeling of short-scale gravity effects in the coastal zone using a combination of topography/bathymetry along with the concept of rock-equivalent topography. RTM data was generated using a new degree-2160 spherical harmonic reference surface that is consistent with the SRTM V4.1/SRTM30_PLUS merged elevation data. We have demonstrated that bathymetry from the SRTM30_PLUS model carries significant information on gravity field structures at spatial scales shorter than 5 arc minutes. This short-scale information was extracted and used to improve gravity functionals from EGM2008 as example of a current high-degree geopotential model, both over land but also adjoining marine areas near the 
coastline. As such, our topography/bathymetry combined modeling offers advantages over topography-only RTM in coastal zones and provides a solution to the "RTM coastal zone problem” that was identified but not solved in Hirt et al. (2010b, paragraphs 31 and 32 ibid.).

The approach, as described and applied in this paper is suitable to compute gravity, geoid undulations and vertical deflections not only over Earth's land masses but also over adjoining coastal zones. This may be of value for some applications.

First, given that many leveling benchmarks and tide gauges are located at or near coast lines, the approach may be used to reduce [to some extent] the signal omission error in height unification or height transfer (e.g., Arabelos and Tscherning 2001) using the EGM2008 geoid or combinations with new GOCE (Gravity field and steady-state Ocean Circulation Explorer, e.g., Pail et al. 2011) data sets. This may be beneficial in coastal areas of scarce gravity data coverage, e.g., parts of Asia. Second, forward-modelled gravity values from combined topography/bathymetry RTM data could fill the gap between land gravity and shipborne gravity along coastlines to some extent, which might be useful for RCR-type regional geoid determination, evaluation of present and future altimetric gravity fields near the shore, or reinforcement of less-dense airborne gravity surveys.

Third, altimetric observations are now being merged with the EGM2008 gravity information over land to allow the calculation of gravity from geoid undulations (Andersen et al. 2010b, p195) or from vertical deflections (Sandwell and Smith 2009 p4) via altimetric convolution integrals. While the 5 arc-min resolution of EGM2008 is largely commensurate with the resolution of recent altimetric gravity fields (Andersen et al. 2010b, Sandwell and Smith 2009), the development of next-generation altimetric gravity fields (Andersen and Stenseng 2012; Sandwell et al. 2011), e.g., based on the Cryosat-2 mission (e.g., Labroue et al. 2012), might require higher-resolution information on the gravity field over land. High-resolution models of geoid undulations or vertical deflections from topography/bathymetry RTM forward-modeling could therefore prove useful for the evaluation of altimetric convolution integrals in coastal zones devoid of dense terrestrial gravity data.

Finally, we note that the RTM performance over marine areas will depend on the amount of depth soundings incorporated in the DBM data, on the roughness of the seafloor topography, and presence of lower-density sediment layers that were not modelled here. 


\section{Acknowledgements}

The Australian Research Council (ARC) is acknowledged for funding this study through Discovery Project grant DP120102441. Christian Hirt is the recipient of an ARC Discovery Outstanding Researcher Award (DORA). Ground-truth data for this study was kindly provided by following institutions and colleagues: Canadian gravity (Gravity \& Geodetic Networks Section, Geodetic Survey Division, Natural Resources Canada), Canadian GPS/levelling (Natural Resources Canada, Marc Véronneau), Greece vertical deflections (ETH Zurich, Dr. Beat Bürki, Dr. Anna Somieski). Sincerest thanks go to all data providers, and to two reviewers for their comments on the manuscript. The spherical harmonic analyses were performed using the freely available software archive SHTOOLS (shtools.ipgp.fr).

Dedication This paper is dedicated to my colleague and friend Prof. Dr. Volker Böder, Professor for Geodesy and Hydrography at HafenCity University Hamburg, who died tragically in a ship collision during a hydrographic survey on 1st September 2012.

\section{Appendix A: Computation of the RET2012 spherical harmonic model}

The following procedure was applied to compute the RET2012 spherical harmonic coefficients

1. The cell-centered 7.5 arc second SRTM V4.1 release was partitioned into $5^{\circ} \times 5^{\circ}$ tiles (2400x2400 cell values) and merged with the SRTM30_PLUS bathymetry. This was done by first [bicubically] interpolating 30_PLUS to 7.5 arc second resolution, then compressing the depths to rock-equivalent topography (RET), before inserting SRTM30_PLUS rockequivalent depths into the SRTM V4.1 at ocean cells as flagged by the SRTM V4.1 sea mask.

2. Outside the SRTM V4.1 coverage, SRTM30_PLUS data is partitioned into $5^{\circ} \times 5^{\circ}$ tiles at 30 arc second resolution (that is, 600x600 cell values), and bathymetric depths are compressed into RET where values are negative.

3. All $5^{\circ} \times 5^{\circ}$ tiles were downsampled to a common resolution of 2 arc minutes $(150 \times 150$ cell values). This was accomplished by applying box-filters to yield $2 \min \times 2$ min cell-mean values (16x16 cell means to reduce the 7.5 arc second tiles, and $4 \times 4$ cell means to reduce the remaining 30 arc second tiles outside the SRTM coverage).

4. For the sake of completeness, we mention that also the inland water masses of the Great Lakes of North America (Superior, Michigan, Huron, Erie and Ontario) and Asia (Baikal and Caspian Sea) were made rock-equivalent using the SRTM30_PLUS inland bathymetry. Icesheets of Antarctica and Greenland, as implied by the ETOPO1-bed and ice products (Amante and Eakins 2009) were made rock-equivalent with the procedures and mass-density values given in Hirt et al. (2012). 
5. A global $2 \times 2$ arc minute grid (5400 x 10800 cell values) was created through seamless mosaicking of all $5^{\circ} \times 5^{\circ}$ tiles.

6. At this point, the $2 \times 2$ arc minute grids were prepared in terms of geodetic coordinates and centre-of-cell registration (5400 x 10800 cell values). For the spherical harmonic analysis with SHTOOLS and Driscoll and Healy's (1994) algorithm, geocentric coordinates and gridline registration is required. Therefore the geodetic latitudes were transformed to geocentric latitude and from centre-of-cell to grid-line registration, requiring (bicubic) interpolation of the data.

7. Finally, the geocentric and grid-line registered grid of cell-mean RET elevations was expanded into spherical harmonics using Driscoll and Healy's (1994) algorithm, as implemented in the SHTOOLS package. In Driscoll and Healy's algorithm, the grid resolution determines the maximum harmonic degree, which is 2699 for our 2 arc minute grids. We did not use the coefficients beyond degree and order 2160, while those complete to 2160 are freely available at http://www.geodesy.curtin.edu.au/research/models.

\section{References}

Amante, C., and B.W. Eakins 2009. ETOPO1 1 arc-minute global relief model: Procedures, Data Sources and Analysis, NOAA Technical Memorandum NESDIS NGDC-24, 19 p.

Andersen, O.B., P. Knudsen, P.A.M. Berry, S. Kenyon, and R. Trimmer. 2010a. Recent developments in high-resolution global gravity field modeling. The Leading Edge May 2010:540-545.

Andersen, O.B., P. Knudsen, and P.A.M. Berry. 2010b. The DNSC08GRA global marine gravity field from double retracked satellite altimetry, Journal of Geodesy 84(3):191-199.

Andersen, O.B., and L. Stenseng. 2012. Global altimetric marine gravity field mapping. The impact of Cryosat-2 data. Presented at General Assembly of the European Geosciences Union Vienna, Austria, 2012, Paper no. 8283.

Arabelos, D., and C.C. Tscherning. 2001. Improvements in height datum transfer expected from the GOCE mission. Journal of Geodesy 75(5/6):308-312.

Balmino, G., K. Lambeck, and W.M. Kaula. 1973. A spherical harmonic analysis of Earth's topography. Journal Of Geophysical Research 78(2):478-481.

Basic, T., and R Rapp. 1992. Oceanwide Prediction of Gravity Anomalies and Sea Surface Heights Using Geos-3, Seasat, and Geosat Altimeter Data and ETOPO5U Bathymetric Data. Report No 426, Department of Geodetic Science and Surveying, Ohio State University, Columbus, USA.

Becker, J.J., D.T. Sandwell, W.H.F. Smith, J. Braud, B. Binder, J. Depner, D. Fabre, J. Factor, S. Ingalls, S-H. Kim, R. Ladner, K. Marks, S. Nelson, A. Pharaoh, R. Trimmer, J. Von 
Rosenberg, G. Wallace and P. Weatherall. 2009. Global Bathymetry and Elevation Data at 30 Arc Seconds Resolution: SRTM30_PLUS. Marine Geodesy 32(4): 355-371.

Bürki, B., A. Müller, and H.-G. Kahle. 2004. DIADEM: The New Digital Astronomical Deflection Measuring System for High-precision Measurements of Deflections of the Vertical at ETH Zurich. In Electronic Proceed. GGSM 2004, IAG International Symposium Porto, Portugal, Also in: CHGeoid 2003, Report 03-33 A, ed. U. Marti et al., Bundesamt für Landestopographie (swisstopo), Wabern, Schweiz.

Claessens, S.J. 2012. Evaluation of gravity and altimetry data in Australian coastal regions, In: Geodesy for Planet Earth, eds. S. Kenyon, C. Pacino, and U. Marti, 435-442, International Association of Geodesy Symposia Vol. 136, Springer Berlin Heidelberg New York.

Dahl, O.C. and R. Forsberg. 1998. Geoid models around Sognefjord using depth data. Journal of Geodesy 72(9):547-556.

Delikaraoglou, D, I. Mintourakis, and F. Kallianou. 2009. Impact of recent Global Digital Bathymetry and Topography Models on geoid modeling: Results from two case studies in Balearic and Aegean Seas. Presented at General Assembly of the European Geosciences Union Vienna, Austria, 2009, Paper no. 3592.

Deng X.L., W.E. Featherstone, C. Hwang, and P.A.M. Berry. 2002. Estimation of contamination of ERS-2 and POSEIDON satellite radar altimetry close to the coasts of Australia. Marine Geodesy 25(4):249-271.

Deng, X.L., W.E. Featherstone, C. Hwang, and C.K. Shum. 2001. Improved coastal marine gravity anomalies in the Taiwan Strait from altimeter waveform re-tracking. In: Proceedings of the International Workshop on Satellite Altimetry for Geodesy, Geophysics and Oceanography, Wuhan, China.

Denker, H., and M. Roland. 2005. Compilation and Evaluation of a Consistent Marine Gravity Data Set Surrounding Europe, In: A window on the Future of Geodesy - Sapporo, Japan, June 30 - July 11, 2003, IAG Symposia Series Vol. 128, 248-253.

Driscoll, J.R., and D.M. Healy. 1994. Computing Fourier transforms and convolutions on the 2sphere Advances in Applied Mathematics 15(2):202-250.

Farr, T.G., P.A Rosen, E. Caro, R. Crippen, R. Duren, S. Hensley, M . Kobrick, M. Paller, E. Rodriguez, L. Roth, D. Seal, S. Shaffer, J. Shimada, J. Umland, M. Werner, M. Oskin, D. Burbank, and D. Alsdorf. 2007. The Shuttle Radar Topography Mission. Reviews Geophysics 45:RG2004.

Featherstone, W.E. 2009. Only use ship-track gravity data with caution: a case-study around Australia. Australian Journal of Earth Sciences 56(2): 191-195.

Featherstone, W.E. 2010. Satellite and airborne gravimetry: their role in geoid determination and some suggestions, In: Airborne Gravity 2010, ed. Lane, R., Geoscience Australia, Canberra. 
Filmer, M.S., C. Hirt, and W.E. Featherstone. 2013. Error sources and data limitations for the prediction of surface gravity: a case study using benchmarks. Studia Geophysica and Geodetica 57(1):47-66, doi: 10.1007/s11200-012-1114-6

Forsberg, R., and C.C. Tscherning. 1981. The use of height data in gravity field approximation by collocation. Journal Geophysical Research 86(B9):7843-7854.

Forsberg, R. 1984. A study of terrain reductions, density anomalies and geophysical inversion methods in gravity field modeling, Report 355, Department of Geodetic Science and Surveying, Ohio State University, Columbus, USA.

Forsberg, R., and A.V. Olesen. 2010. Airborne Gravity Field Determination. In: Sciences of Geodesy - I, ed. G. Xu, 83-104, Springer-Verlag Berlin Heidelberg.

Hirt, C. 2010. Prediction of vertical deflections from high-degree spherical harmonic synthesis and residual terrain model data. Journal of Geodesy 84(3): 179-190.

Hirt, C. 2012. Efficient and accurate high-degree spherical harmonic synthesis of gravity field functionals at the Earth's surface using the gradient approach. Journal of Geodesy, 86(9):729-744.

Hirt, C., W.E. Featherstone, and U. Marti. 2010a. Combining EGM2008 and SRTM/DTM2006.0 residual terrain model data to improve quasigeoid computations in mountainous areas devoid of gravity data. Journal of Geodesy 84(9): 557-567.

Hirt, C., U. Marti, B. Bürki, and W.E. Featherstone. 2010b. Assessment of EGM2008 in Europe using accurate astrogeodetic vertical deflections and omission error estimates from SRTM/DTM2006.0 residual terrain model data. Journal Geophysical Research 115:B10404.

Hirt, C., M. Kuhn, W.E. Featherstone, and F. Göttl. 2012. Topographic/isostatic evaluation of new-generation GOCE gravity field models. Journal Geophysical Research 117: B05407.

Holmes, S.A., and N.K. Pavlis. 2008. Spherical harmonic synthesis software harmonic_synth. Available at: http://earth-info.nga.mil/GandG/wgs84/gravitymod/egm2008/index.html.

Hwang, C., J. Guo, X. Deng, H.Y. Hsu, and Y. Liu. 2006. Coastal gravity anomalies from retracked Geosat/GM altimetry: improvement, limitation and the role of airborne gravity data. Journal of Geodesy 80(4):204-216.

Jarvis, A., H.I. Reuter, A. Nelson, and E. Guevara. 2008. Hole-filled SRTM for the globe Version 4, Available from the CGIAR-SXI SRTM 90m database. Available at: http://srtm.csi.cgiar.org.

Kuhn, M., and W.E. Featherstone. 2003. On the Construction of a Synthetic Earth Gravity Model, In: Proceed 3rd Meeting of the Intern. Gravity and Geoid Commission, ed. I Tziavos, 189-194. Editions Ziti.

Labroue, S., F. Boy, N. Picot, M. Urvoy, and M. Ablain. 2012. First quality assessment of the Cryosat-2 altimetric system over ocean. Advances in Space Research 50(8):1030-1045. 
Limpach, P. 2009. Sea Surface Topography and Marine Geoid by Airborne Laser Altimetry and Shipborne Ultrasound Altimetry in the Aegean Sea, Diss. ETH No. 18225, ETH Zurich, Switzerland.

Müller, A., B. Bürki, P. Limpach, H.-G. Kahle, V.N. Grigoriadis, G.S. Vergos, and I.N. Tziavos 2007. Validation of marine geoid models in the North Aegean sea using satellite altimetry, marine GPS data and astrogeodetic measurements. In: Proceed. of the 1st International Symposium of the International Gravity Field Service, 90-95, Harita Dergisi, Special Issue 18, Istanbul, Turkey.

Nagy, D., G. Papp, and J. Benedek. 2000. The gravitational potential and its derivatives for the prism. Journal of Geodesy 74(7):552-560, Erratum in Journal of Geodesy 76(8):475.

NRC 2011. Canadian gravity data base. Natural Resources Canada, Canada. Available at: http://gdcinfo.agg.nrcan.gc.ca/cat/indexgrav_e.html.

Pail, R., S. Bruinsma, F. Migliaccio, C. Förste, H. Goiginger, W.-D. Schuh, E. Höck, M. Reguzzoni, J.M. Brockmann, O. Abrikosov, M. Veicherts, T. Fecher, R. Mayrhofer, I. Krasbutter, F. Sansò, and C.C. Tscherning. 2011. First GOCE gravity field models derived by three different approaches. Journal of Geodesy 85(11):819-843.

Pavlis, N.K., J.K. Factor, and S.A. Holmes. 2007. Terrain-related gravimetric quantities computed for the next EGM. In: Proceed. of the 1st International Symposium of the International Gravity Field Service, 318-323, Harita Dergisi, Special Issue 18, Istanbul, Turkey.

Pavlis, N.K., S.A. Holmes, S.C. Kenyon, and J.K. Factor. 2012. The development and evaluation of the Earth Gravitational Model 2008 (EGM2008). Journal Geophysical Research 117, B04406.

Rapp, R.H. 1997. Use of potential coefficient models for geoid undulation determinations using a spherical harmonic representation of the height anomaly/geoid undulation difference. Journal of Geodesy 71(5):282-289.

Rummel, R., R.H. Rapp, H. Sünkel, and C.C. Tscherning. 1988. Comparisons of global topographic/isostatic models to the Earth's observed gravity field. Report No 388, Department of Geodetic Science and Surveying, Ohio State University, Columbus, USA.

Smith, W.H.F., and D.T. Sandwell. 1997. Global sea floor topography from satellite altimetry and ship depth soundings. Science 277:1956-1962.

Sandwell, D.T., and W.H.F. Smith. 2009. Global marine gravity from retracked Geosat and ERS1 altimetry: Ridge Segmentation versus spreading rate, Journal Geophysical Research 114, B01411.

Sandwell, D.T., E.S. Garcia, and W.H. Smith. 2011. Improvement in Global Marine Gravity from CryoSat. American Geophysical Union, Fall Meeting 2011, abstract \#C41A-0384.

Somieski, A.E. 2008. Astrogeodetic Geoid and Isostatic Considerations in the North Aegean Sea, Greece, Diss. ETH No. 17790, ETH Zurich, Switzerland. 
Šprlák, M., C. Gerlach, and B.R. Pettersen. 2012. Validation of GOCE global gravity field models using terrestrial gravity data in Norway. Journal of Geodetic Science, 2(2): 134143.

Sproule, D.M. 2005. Prediction of offshore gravity from bathymetry. PHD Dissertation, School of Surveying and Spatial Information Systems, University of New South Wales, Sydney, Australia

Sproule, D.M., A.H.W. Kearsley, and R. Forsberg. 2003. Bathymetric data to increase resolution of gravity data. In: Proceed 3rd Meeting of the Intern. Gravity and Geoid Commission, ed. I Tziavos, 57-60. Editions Ziti.

Tocho, C., G.S. Vergos, and M.G. Sideris. 2005. Optimal marine geoid determination in the Atlantic coastal region of Argentina. In: A window on the Future of Geodesy - Sapporo, Japan, June 30 - July 11, 2003, IAG Symposia Series Vol. 128, 380-385, Springer Berlin Heidelberg New York.

Tocho, C., G.S. Vergos, and M.G. Sideris. 2012. Investigation of topographic reductions for marine geoid determination in the presence of an ultra-high resolution reference geopotential model. In: Geodesy for Planet Earth, eds. S. Kenyon, C. Pacino, and U. Marti, 419-426, International Association of Geodesy Symposia Vol. 136, Springer Berlin Heidelberg New York.

Torge, W. 2001. Geodesy, $3^{\text {rd }}$ Edition. De Gruyter, Berlin, New York.

Tziavos, I.N., G.S. Vergos, and V.N. Grigoriadis. 2010. Investigation of topographic reductions and aliasing effects to gravity and the geoid over Greece based on various digital terrain models. Surveys in Geophysics 31(3):23-67.

Vergos, G.S., and M.G. Sideris. 2003. Estimation of high-precision marine geoid models offshore Newfoundland, Eastern Canada. In: Proceed 3rd Meeting of the Intern. Gravity and Geoid Commission, ed. I Tziavos, 126-131. Editions Ziti.

Vergos, G.S., and M.G. Sideris. 2005. Improvement in the Determination of the Marine Geoid by Estimating the Bathymetry from Altimetry and Depth Soundings. Marine Geodesy 28(1):81-102.

Véronneau, M., R. Duval, and J. Huang. 2006. A gravimetric geoid model as a vertical datum in Canada. Geomatica 60(2):165-172.

Véronneau, M. 2007. Adjustment of Levelling Data in Canada: Nov07, Report, Geodetic Survey Division, Natural Resources Canada.

Wessel, P., and M.T. Chandler. 2011. The spatial and temporal distribution of marine geophysical surveys. Acta Geophysica 59(1):55-71. 